\title{
The rescue of seismic field data from exploration activities in the Danish North Sea
}

\author{
Marianne M. Hansen and Nicolai Rinds
}

In 2009, the Danish Energy Agency informed the Geological Survey of Denmark and Greenland (GEUS) that a new legal act (Lov om fordring/Forældelsesloven) would become effective in 2011. The new act introduced a limitation period of three years on the government's right to request data from licensees' oil and gas activities in Denmark (www.retsinformation.dk 2007), and it became the catalyst for a major change in the standard procedure for licensees' submission of seismic data related to exploration activities to GEUS. A consequence of the new legal act was that the Danish authorities would have to request data from the licensee (following the Consolidated Act of the Use of the Subsoil) from the licensee no later than three years after their generation or publication; otherwise the authorities would have no legal right to the data. It was emphasised by the Danish Energy Agency that GEUS would have to submit all requests for outstanding data to the licensees no later than 1 January 2011.

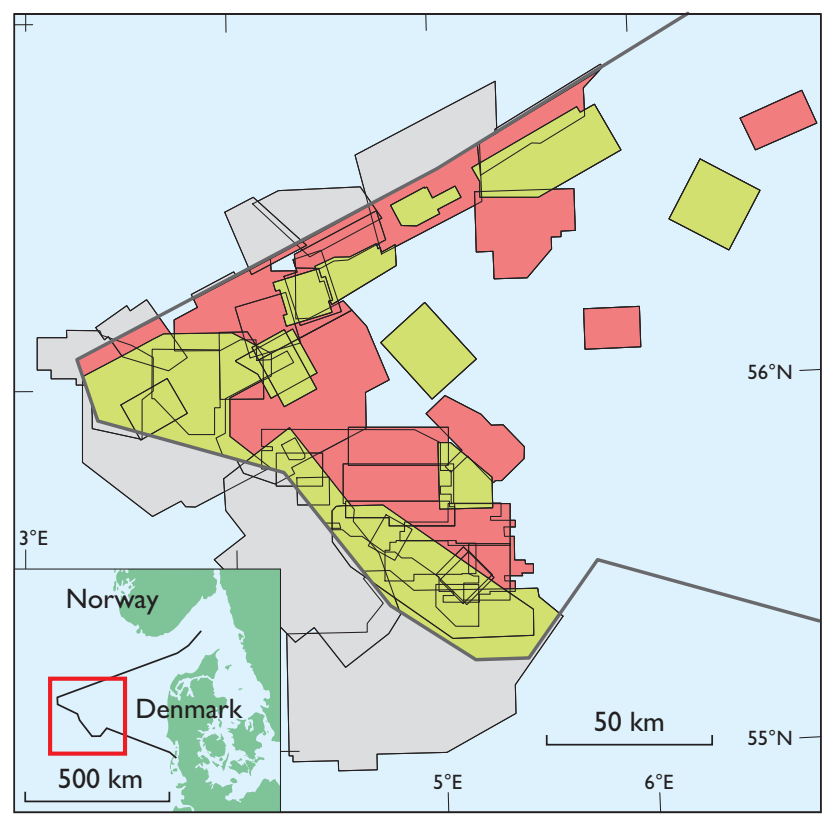

Fig. 1. 3D seismic field data status prior to the rescue project. Green polygons: field data in GEUS' archive. Red polygons: field data not in GEUS' archive. Grey polygons: parts of seismic surveys outside the Danish sector.
During the 1980s and 1990s the standard procedure for data requests from GEUS did not include pre-stack seismic data, e.g. raw field data. A search in GEUS database showed that field data had been received from only a small percentage of existing 2D and 3D surveys (Fig. 1). Being the national data bank for geological data, GEUS had to respond to this risk of losing access to valuable data, and immediate action was needed.

\section{The National Well Data and Subsurface Archives}

GEUS and its Danish predecessor the Geological Survey of Denmark (DGU) have systematically collected and stored geological data from Denmark for more than a 100 years. The idea of establishing a national data bank for geological data arose in the 1920s when Danish law made it mandatory for everyone drilling in search for water to register certain geological information encountered during drilling and deliver it to DGU. The Well Data Archive was established in 1926 to fulfil this purpose (Troelstrup 1992). The search for oil in Denmark began onshore in 1935. Until the beginning of the 1980s data submitted to DGU from oil and gas activities were stored in the Well Data Archive. For many years only few companies searched for oil in the Danish sector. In 1962, the Danish company A.P. Møller $\mathrm{A} / \mathrm{S}$ was granted exclusive rights to explore the Danish subsoil according to the Sole Concession of 8 July 1962 (North

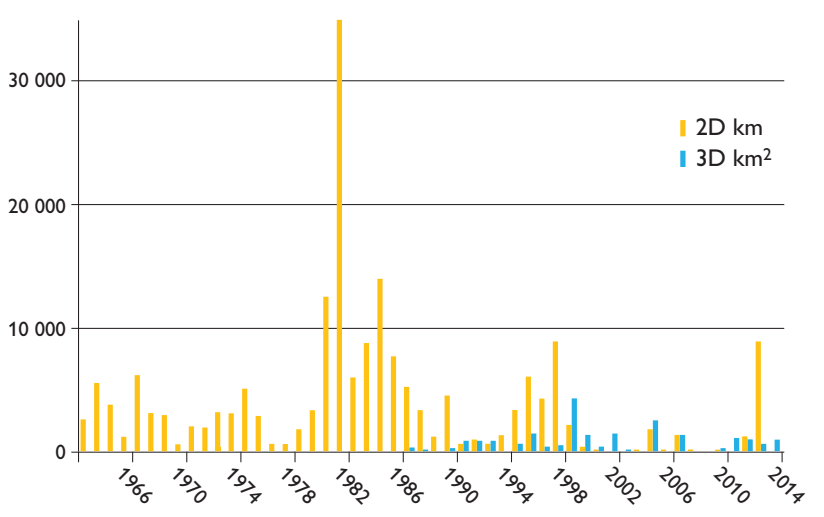

Fig. 2. Annual seismic survey activities in Denmark 1962-2014. 
Sea Fund 2012). This was renegotiated in 1981, and a large concession area was relinquished. In 1984 the first competitive licensing round resulted in an increased search for oil, and the submission of data to DGU increased (Fig. 2, extracted from GEUS' database).

In the beginning of the 1980s, it was decided that a separate archive should be established - the Subsurface Archive - to store oil- and gas-related data (Kristoffersen 1995, 2017). The decision was made in order to fulfil increased requirements for a secure data environment and to control the strict confidentiality regulations applying to exploration and production data.

\section{Data usage}

Until 1980, DGU did not request digital seismic data from, the companies as part of its standard procedure. This was primarily due to the fact that only paper copies of seismic sections were used for in-house interpretation. Furthermore, space for in-house storage was very limited, and the data owners themselves were obliged to store their digital field data for a period of time and to offer the data to DGU if they decided to discard them. At that time the data were stored on vast numbers of 9-track tapes. In general, the oil companies did not use digital data either, and if such data were requested it was often on a single line basis.

By 1990, workstations had become a standard tool for interpretation and geophysical mapping in the oil industry, and access to the digital data became necessary. Therefore digital processed seismic data were added to DGU's standard data request, but their handling was a huge and timeconsuming task. Licensees or companies were asked only to

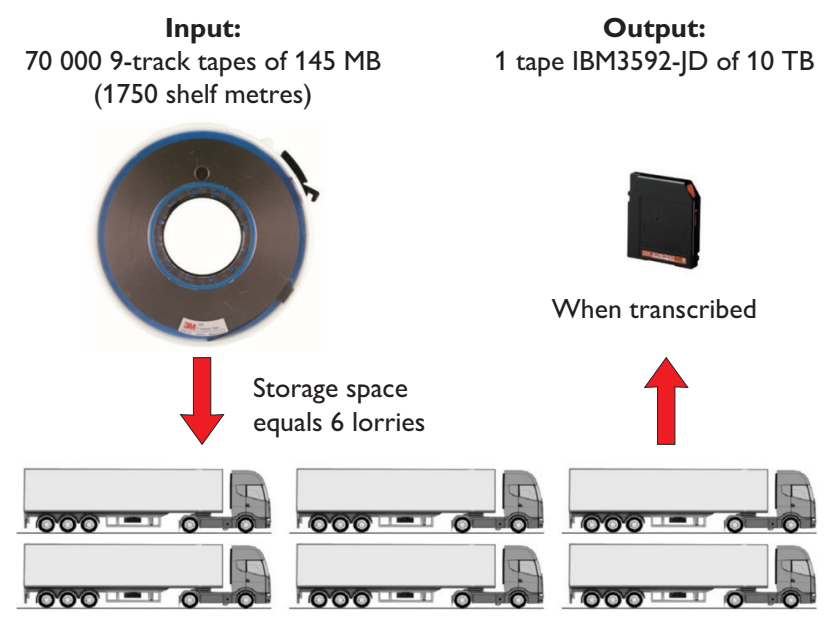

Fig. 3. Space reduction with the use of modern tapes media. Source: OvationData 2017. submit specific digital seismic data when they were needed for in-house interpretation, or if a specific request arrived from an external customer. As a consequence, DGU did not have a complete collection of digital processed seismic data at the time.

Until the 1990s, most of the seismic field data submitted to DGU came from relinquished or expired licences. In these cases, the data holders could decide to keep the seismic field data themselves or offer the data to DGU. Although the authorities have always been able to request copies of the seismic field data this was not listed as a mandatory requirement until 2002 (Danish Energy Agency 2002).

\section{Data media and volumes}

The development of 3D data acquisition methods in the late 1980s resulted in an increasing amount of tapes being submitted to DGU. During the last 20 years, digital seismic data have regularly been submitted to the Subsurface Archive and maintenance of these data has been a constant challenge. The long-term use of the digital data can only be secured by keeping the data from degrading, by rewinding the 9-track tapes or transcribing the data to a new media on a regular basis.

The oil industry has frequently changed their 'standard tape media', in order to secure the very expensive collected data and to reduce the storage space needed on board vessels and in archives. The most commonly used storage medium in the 1980s and 1990s was 9-track tapes. In the mid-1990s, more compact types appeared such as Exabyte, DAT and various versions of IBM tapes, which were smaller and could contain much more data per volume. This had a tremendous impact on the number of shelf metres needed for storage. For instance, one modern IBM3592-JD tape contains the same amount of data as 70000 high-capacity 9-track tapes, which would require 1750 archive shelf metres (Fig. 3).
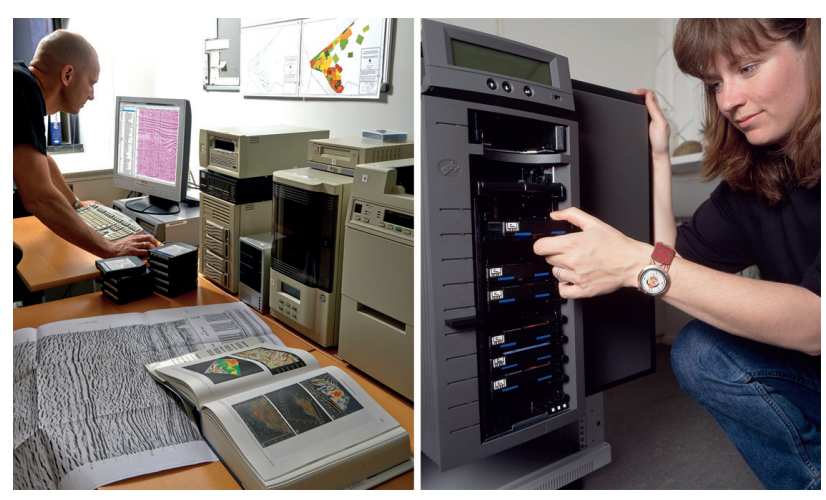

Fig. 4. Seismic data and tape drives at GEUS. 
Over time, GEUS has purchased various kinds of tape drives to be able to read the data and (on a small scale) make backup copies. In 2000, the Subsurface Archive contained data stored on up to 10 different tape media types, but mostly on $c .150009$-track tapes, including both seismic and well data, as well as data acquired in Greenland waters. The archive also contained 3000 Exabyte, DAT and LTO tapes and 5000 IBM tapes of various kinds.

At GEUS tape copying is considered a specialist job since up-to-date equipment and specialised treatment of deteriorating 9-track tapes are required, and the task is very time consuming, expensive and never-ending. Furthermore, vintage tape drives are difficult to maintain and acquisition of spare parts almost impossible. Since 2002, GEUS has used an external company for all tape copying jobs. A few in-house tape drives are still being used and maintained for internal purposes (Fig. 4).

\section{The data rescue project}

After GEUS was made aware of the new Act and its consequences, it was decided in 2010 to start a project to rescue older seismic field data. The aim was to rescue i.e. locate, receive and store either the original or a copy of the seismic data from all oil- and gas-related activities in Denmark. The plan was within the first year to contact all companies which had been operators or had acquired data in the Danish sector between 1980 and 1999. The plan for the following two years was to perform quality control of the submitted data, with completion of the project within three years.

The following priorities were set up: field data were considered more important than processed data. 3D data were considered more valuable than 2D data. Finally, onshore 2D data were considered more important than offshore 2D data, and data acquired from 1990 to 2000 were considered to be more valuable than older data. A search in GEUS' database showed that almost no field data from before 1995 had been received, and that some field data had been received between 1995 and 2002 .

\section{Worst-case scenario}

A worst-case scenario in terms of expenditure and workload for GEUS was considered, assuming that all the companies chose to give up all their original field tapes and submit them to GEUS. It might be expected from the age distribution that most data might still be stored on the original 9-track tapes. If GEUS had to accept these directly, the Subsurface Archive would need large additional resources to cover the costs of external storage or for transcription
Table 1. Estimated copying cost worst-case scenario ${ }^{\dagger}$

\begin{tabular}{lrrrr}
\hline Survey type & $\begin{array}{c}\text { Total km in } \\
\text { Denmark }\end{array}$ & No. of tapes & DKK per tape & DKK total \\
\hline 2D & 3405 & 3405 & 140 & 476700 \\
3D & 156234 & 156234 & 140 & 21872760 \\
Total cost & & & & 22349460 \\
\hline
\end{tabular}

†Assuming: All field data from 1995 and earlier are located. All data are stored on 9 -track tapes. Data are 60 -fold. There is $1 \mathrm{~km}$ of data per tape.

to an in-house, modern storage medium. A rough calculation showed that if all the missing field data were submitted, GEUS could receive more than 190000 tapes, out of which 170000 were likely to be 9-track tapes. The cost of transcription was estimated to $c$. DKK 23 million (Table 1). Alternatively, if all the 1700009 -track tapes were to be stored in-house the Subsurface Archive would need 4350 additional shelf metres.

After making a list of 2D and 3D surveys from which the seismic field data had not been submitted, a priority list consisting of $483 \mathrm{D}$ surveys and $402 \mathrm{D}$ surveys was made. The next step was to contact the companies involved, but it proved difficult to locate some of the companies and relevant contact persons. In 2002, GEUS had sent requests for data to all licensees in the Danish sector, typically to the company headquarters without a specific contact person. The outcome of this campaign was unfortunately almost

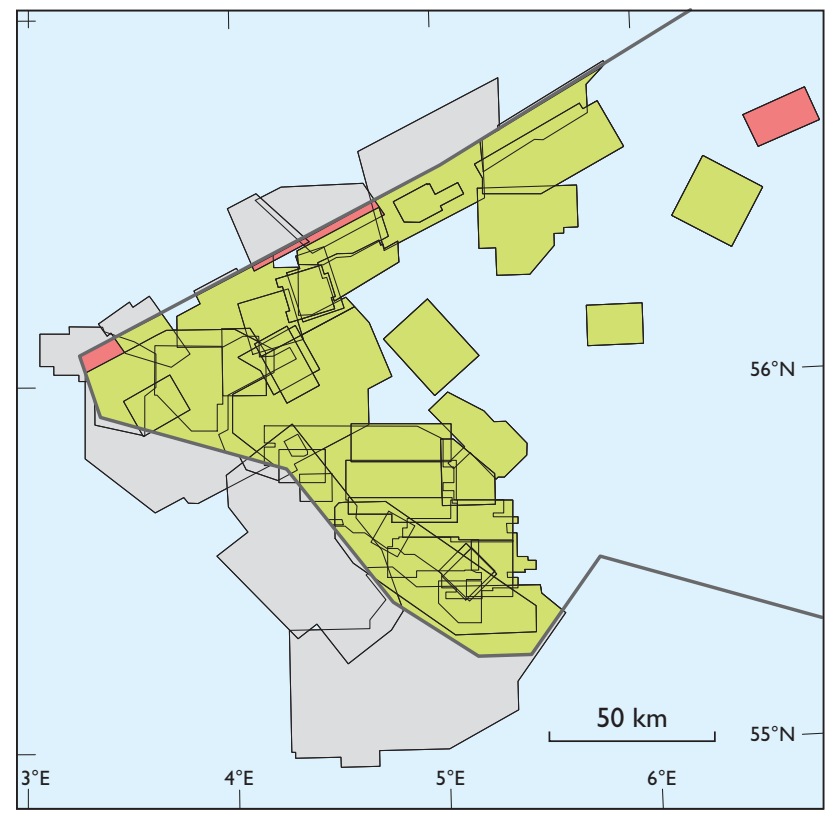

Fig. 5. 3D field data status after the rescue project. For location and polygon colours, please see Fig. 1. 
nill. The oil industry is a rapidly changing business, and some of the companies which had been active in the Danish sector in the 1970s or 1980s no longer existed or had been taken over by or merged with other companies. Keeping track of a company can be strenuous and time consuming, and the subsequent search for a relevant contact person was even more difficult.

\section{Results and achievements}

As part of the data rescue project, 17 companies were contacted during 2010 and 2011. In general their responses to locate and deliver the missing data have been positive and cooperative. The project benefitted from the fact that two of the older oil companies are still operating in the Danish sector, since both Mærsk Olie og Gas A/S (Mærsk) and DONG Energy E\&P A/S (DONG) have been in charge of, or involved in, data acquisition for many years. The most time-consuming part of this project turned out to be the quality control of the received data due to insufficient documentation, e.g. erroneous transmittals or missing acquisition and processing reports.

The recovery process was initiated in 2010 by meetings with the two companies, whereby a large number of surveys from the priority list could be ticked off, and the focus then shifted towards contacting the owners of the remaining data.

Mærsk and DONG decided to transcribe their original data themselves to modern media types. Given the large quantities of data and tapes, this task was very time consuming. It took several years before the copying jobs were finalised and tapes could be submitted to GEUS, but it had the benefit that GEUS received all data on modern media types (IBM 3592 tapes or USB disks). Initially, high-priority 3D field data from 34 of the 48 3D surveys on GEUS' priority list were missing; to date GEUS has located $82 \%$ of the missing surveys and received data from $74 \%$ of them (Fig. 5). GEUS has also received some missing processed data. Because of the above-mentioned complications, the recovery project lasted six years instead of the anticipated three, with a time consumption of $c .1600$ man hours at GEUS. Over a six-year period GEUS has spent $c .1$ million DKK on external copying.

\section{Lessons learnt and conclusions}

In hindsight, the timing of the rescue project was optimal. Between 2010 and 2014 the world experienced high oil prices (www.macrotrends.net 2017), which is likely to have encouraged the oil companies, especially Mærsk and DONG, to transcribe their original field tapes to modern media. The companies took the opportunity to recover their vintage data and thereby also save future storage costs. If the project was to be started today, the companies might have had other priorities and it might not have been possible for GEUS to keep the copying costs at a relatively low level compared to the worst-case scenario.

To rescue seismic field data is both a cumbersome and potentially expensive task. However, seismic field data represent a valuable asset for evaluation of the hydrocarbon potential of a given area. New companies in the Danish sector, especially smaller companies, commonly request field data from both 2D and 3D seismic surveys in order to reprocess existing data prior to committing themselves to acquisition of new seismic data. The access time to the field data is optimised, since the rescue project has provided GEUS with most of the field data requested by the companies. The data can also be used in future scientific studies. It is therefore an important task for a geological survey like GEUS to secure these data by making it a high priority to request and secure all data which are acquired from the Danish subsurface.

\section{References}

Danish Energy Agency 2002: Danish Executive Order No. 56 of February 4, 2002 Executive Order on Submission of Samples and Other Information about the Danish Subsoil. Danish Executive Order No. 56. [Unofficial translation]. https://ens.dk/sites/ens.dk/files/OlieGas/ submission_samples_other_info_danish_subsoil.pdf

Kristoffersen, F.N. 1995: DGU's undergrundsarkiver [DGU's Subsurface archives]. In: Binzer, K. (ed.): Annual report 1994. Copenhagen: Geological Survey of Denmark, 102-105 [in Danish].

Kristoffersen, F.N. 2017: Undergrundsarkiv - fra kaos til moderne databank [The Subsurface Archive - From chaos to modern data bank]. Hundested, 1 p. [Unpublished report in Danish].

North Sea Fund 2012: Brief History of Danish Oil \& Gas Exploration 1984 - 2011 - Licensing Rounds 1-6. Renewed Interest in Hydrocarbon Exploration in Denmark. Ahead of the 7th Round in 2013, 14 pp.

Troelstrup, S. 1992: The national geological databank. In: Binzer, K. (ed.): Annual report 1991. Copenhagen: Geological Survey of Denmark, 45-47.

www.macrotrends.net 2017: http://www.macrotrends.net/2516/wti-crudeoil-prices-10-year-daily-chart

www. retsinformation.dk 2007: LOV nr 522 af 06/06/2007 (Forældelsesloven) - Historisk. https://www.retsinformation.dk/Forms/R0710. aspx?id=2655 [in Danish - no translation available]. 